\title{
Analysis of Well Log Data for the Evaluation of Gas Sand Reservoir of Alam El-Bueib (AEB) Formation, 3G Member, Jade-8 Well, Jade Field, Matruh Basin, Egypt
}

\author{
Basal, A.M.K ${ }^{1}$ and El-Twargy, E.A.*1 \\ ${ }^{1}$ Geology Department, Faculty of Science, Damietta University, New Damietta, Egypt \\ Received: 21 February 2018 /Accepted: 12 March 2018 \\ * Corresponding author: esraaeltwargy@du.edu.eg
}

\begin{abstract}
The evaluation of gas reservoirs in Alam El Bueib has been dealt with through the interpretation of well log data. Alam El-Bueib (AEB) formation is monitored in Matruh basin at the Northern part of the Western Desert, Egypt encountered many gas producing reservoirs. Alam El- Bueib - 3G (AEB - 3G) member was chosen for application of the presented techniques. The available well log data are in the form of Gamma Ray, Bit size, Caliper, Resistivity, Neutron, Density, Sonic and Photoelectric. The reservoir petrophysical parameters $\left(\Phi_{\text {eff }}, \mathrm{Sw}, \mathrm{Bvw}\right)$ besides mineralogical make up were evaluated for this member in JADE - 8 well. The gas zone represents a challenge for well log interpretation technique as they normally plotted above the standard porosity lines. A graphical technique was used to get $\Phi_{\text {eff }}$ in the zones on the $\rho_{b}-\Phi N$ cross plot. The Sw Vs $\Phi$ was presented graphically on $\log -\log$ plot for obtaining BVW constant lines. Line with slope unity discriminates between reservoir and non-reservoir for $\mathrm{AEB}$ - 3G member.

Keywords: Gas sand reservoir, Alam El-Bueib, $3 \mathrm{G}$ member, Matruh Basin, Well logging, Western Desert, Egypt.
\end{abstract}

\section{Introduction}

The Western Desert comprises the area westwards from the Nile Valley and Delta and extended to the Libyan borders. The petroleum province of the Western Desert has a major hydrocarbon potentiality as recent discoveries indicated (Abu El Naga 1984); six different Mesozoic basins exist in the northern Western Desert; namely Matruh, Shoushan, Alamein, Qattara, Abu El Gharadig, and Kattaniya (Fig.1). Matruh Basin lies in the North Western part of the Western Desert and has a NNE-SSW direction inherited from reactivated Palaeozoic fabric (Moustafa et al., 2002). The basin history shows an early rifting phase during the Jurassic and Early
Cretaceous when excellent Jurassic (Khatatba formation) and Lower Cretaceous (Alam El Bueib) source rocks were deposited with total organic carbon (TOC) values up to $10 \%$ and $5 \%$ respectively (Moustafa 2008). This article is focused on evaluation of Alam El Bueib 3G member (AEB - 3G) gas producing reservoir, Jade field. This field is located in the north Western Desert of Egypt, about $50 \mathrm{~km}$ south of Matruh City. It lies between latitudes $31^{\circ} 56^{\prime} 24^{\prime \prime}$ to $31^{\circ}$ $57^{\circ} 36^{\prime \prime} \mathrm{N}$ and longitudes $25^{\circ} 24^{\prime} 20^{\prime \prime}$ to $25^{\circ} 25^{\circ}$ 45 ” E (Fig.1). 


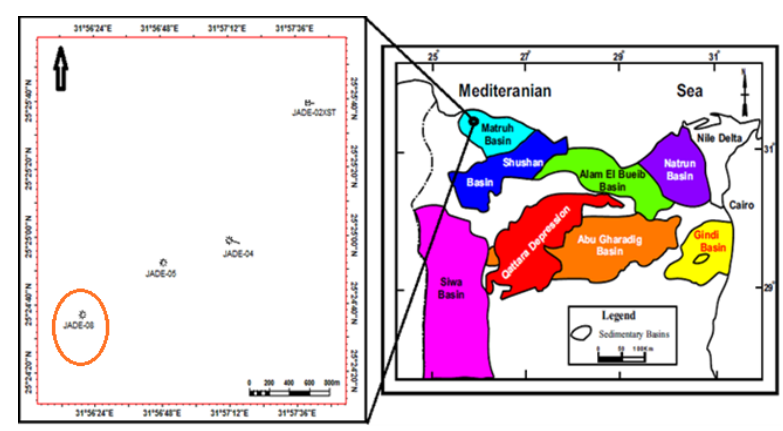

Fig.1: Location map showing the sedimentary basins in the Western Desert of Egypt (EGPC, 1992) and the study well (Jade-8) in Jade field, Matruh Basin, North Western Desert, Egypt.

\section{Stratigraphy of the Study area:}

The stratigraphic column of the Northern Western Desert comprises a sedimentary succession from Ordovician to recent unconformable overlying Pre-Cambrian basement rocks (EGPC 1992,Fig.2). This succession is subdivided into four major regressive cycles; each one is terminated by a marine transgression. Alam El- Bueib Formation is subdivided into six units (1 to 6). Unit three is further subdivided into seven members from (A to G) (EGPC 1992). This formation belongs to the second cycle which began at Early Cretaceous with the deposition of (units 6 and unit 5) shallow marine clastics at the base followed by (unit 4) with marine shale and (unit 3) which includes a succession of massive fluvial sand bodies separated by marine shale incursions. These sand bodies are overlain by (units 2 and 1) alternating shale, sandstone, and marine shelf carbonates and ends in the Alamein Dolomite. Dahab Shale marks the end of this cycle (Sultan and Halim 1988). The main gas producing reservoir is Alam El Buieb, 3G member (AEB $3 G)$. It is mainly clastics varying from fine to coarse grain sandstones.

\section{Structural features of the study area:}

The most predominant structures in the study area are the NE to ENE folding trend associated with reverse faulting. Most of those faults originated during late cretaceous to early tertiary while the E$\mathrm{W}$ faults exhibit evidence of strike slip movements along the old faults (Sultan and Abd El - Halim, 1988). Bounding faults of Matruh basin orientation indicates NE-SSW trend (Fig.3) (Moustafa 2008).

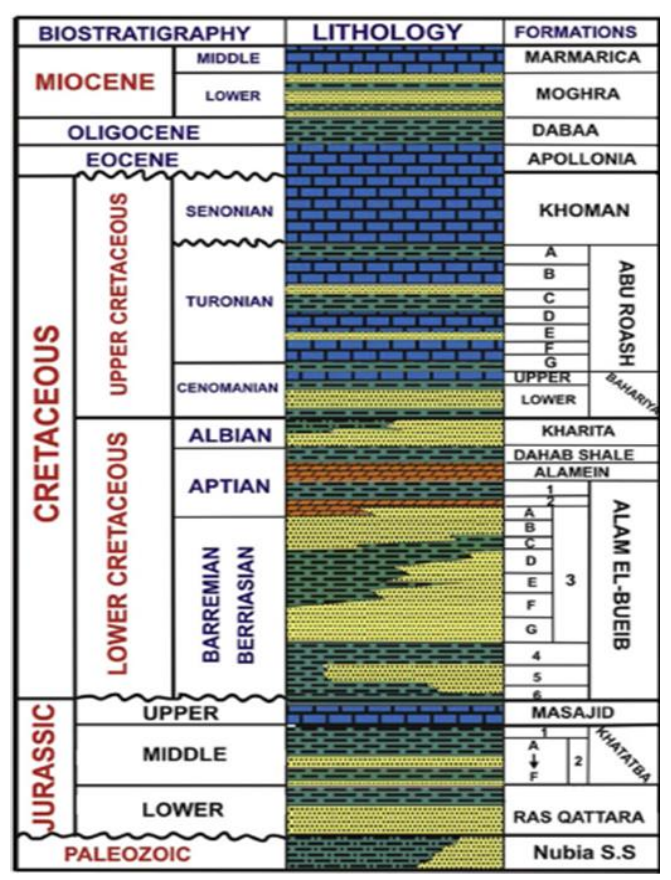

Fig.2: Generalized lithostratigraphic column of North Western Desert, Egypt. (Schlumberger, 1995)

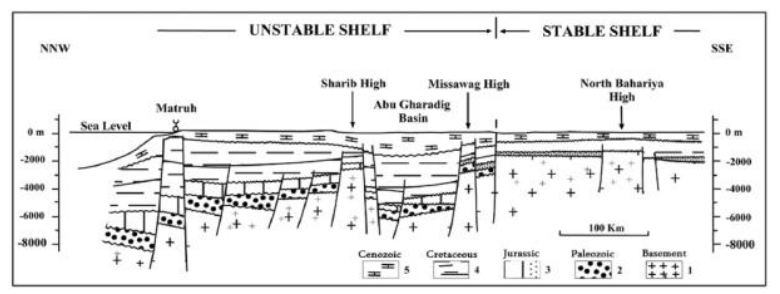

Fig.3: Schematic geological cross section along northwestern Egyptian NNW-SSE direction (Guiraud and Bosworth, 1999)

\section{AIM OF THE STUDY}

The main aims of this investigation can be summarized in the following:

(i) Locating and identifying Gas zones,

(ii) Define the reservoir matrix composition,

(iii) Evaluation of the static reservoir parameters (Sw, Vsh, $\Phi)$,

(iv) Detecting and discrimination between movable and residual hydrocarbons,

(v) Detecting reservoir performance through evaluating Irreducible Water Saturation (SWirr) by applying BUCKLE technique ( $\phi$ vs $\mathrm{Sw}$ ) Using computer program facilities in the form of Interactive Petrophysics (IP) for enhancing and accelerate computing processes with higher accuracy.

\section{3- Data of the Study:}

A complete set of wire line well log data of the selected wells (Jade- 8) (Fig.1) were kindly provided by Khalda Petroleum Company (KPC). 
These logs are in the form of Gamma Ray (GR), Bit size (BS), Caliper (CALI), Resistivity, Neutron, Density, Sonic and Photoelectric. Enlarge this section by adding some description of the study data, like method of recording, dates, companies ....... You could also write about the use of the logs to study so ....I.e; Gamma ray logs were used to .etc.

\section{VISUAL DESCRIPTION OF THE WELL LOG DATA}

The first step before any detailed well log data interpretation is to describe qualitatively, the $\log$ curve response to pick which intervals are promising to be potentially hydrocarbon bearing. The well log curve deflections reflects the effect of the contained matrix, shalines?, porosity and fluids. It is of prime importance to integrate and correlate all the curve shapes with standard reference values. The following section represent quick look interpretation for the available well log data provided in LAS format. The files are loaded to the IP program and displayed in analog format for Jade-8 (Fig.4)

\section{Qualitative interpretation of well logs:}

The following is a detailed qualitative interpretation for the log curve shapes for AEB 3G member in Jade-8 well:

The clearly positive separation between resistivity curves (RD>> Rs >>RMIL) seen at the top of this member down to 10230 feet indicate the presence of $\mathrm{f}$ invasion profile characterizing good porosity and permeability with hydrocarbon. The low GR seen on track 3 ( $<30$ API) reflects the clean nature of the reservoir. Presence of mud cake is evidenced as the caliper reads equal or slightly less than bit size. This mud cake confirm good reservoir quality

The abrupt decrease in all resistivity curves seen at $10230 \mathrm{Ft}$. when both (RD) and (Rs) track each other and continued decreasing down to the rest of the section. This point mark the Gas - water contact (G.W.C). The clean $100 \%$ wet zone is separated from the above gas one by a relatively thick shale interval (10230-10270, GR > 60 API), $\mathrm{Pe} \approx 2.5$ ) and marked by low GR, PE $=1.98$, Neutron - Density separation of about 4 P.u with neutron at the right.

It is very interesting to notice that, at the water zone (no gas effect) the separation between Neutron-Density is reduced to standard sandstone matrix effect. Hence the same sandstone contained both gas and water; the effective porosity can be picked directly on the neutron scale at the midpoint between the two curves in the water zone. In this case the reservoir porosity is about $15 \%$.

The deep resistivity reads about $0.7 \Omega \mathrm{m}^{2} / \mathrm{m}$ at $(10280-10360 \mathrm{ft})$. Note that opposite gas interval $\mathrm{RD}$ reads $>200 \Omega \mathrm{m}^{2} / \mathrm{m}$. (Caliper $\leq$ Bit size) this confirms the presence of mud cake and the resistivity separation as described above.

The sandstone matrix is expected to be the main lithology for the described AEB -3G as the PE curve (track 5) reads almost $(1.98-2 \mathrm{~B} / \mathrm{E})$ of typical sandstone value (Fig.4).

The gas effect can be easily picked on the $(\mathrm{CNCF}$ - ZDNC) separation (track 5) (i.e. neutron and density reads too low values with CNCF on the right relative to $\mathrm{ZDNC}$ ).

A quick look calculation for the connate water resistivity (Rw) can be conducted through the porosity and resistivity values at $100 \%$ water zone at $(10280-10360 \mathrm{ft})$. The deep resistivity read is $(\mathrm{RD}=0.7)$ which represent $\mathrm{Ro}(\mathrm{Rt}=\mathrm{Ro}$ at $\mathrm{Sw}=$ 100\%). From Archie (1942) equation:

$\mathrm{R}_{\mathrm{o}} / \mathrm{R}_{\mathrm{w}}=\mathrm{a} / \Phi^{\mathrm{m}} \ldots \ldots \ldots \ldots$

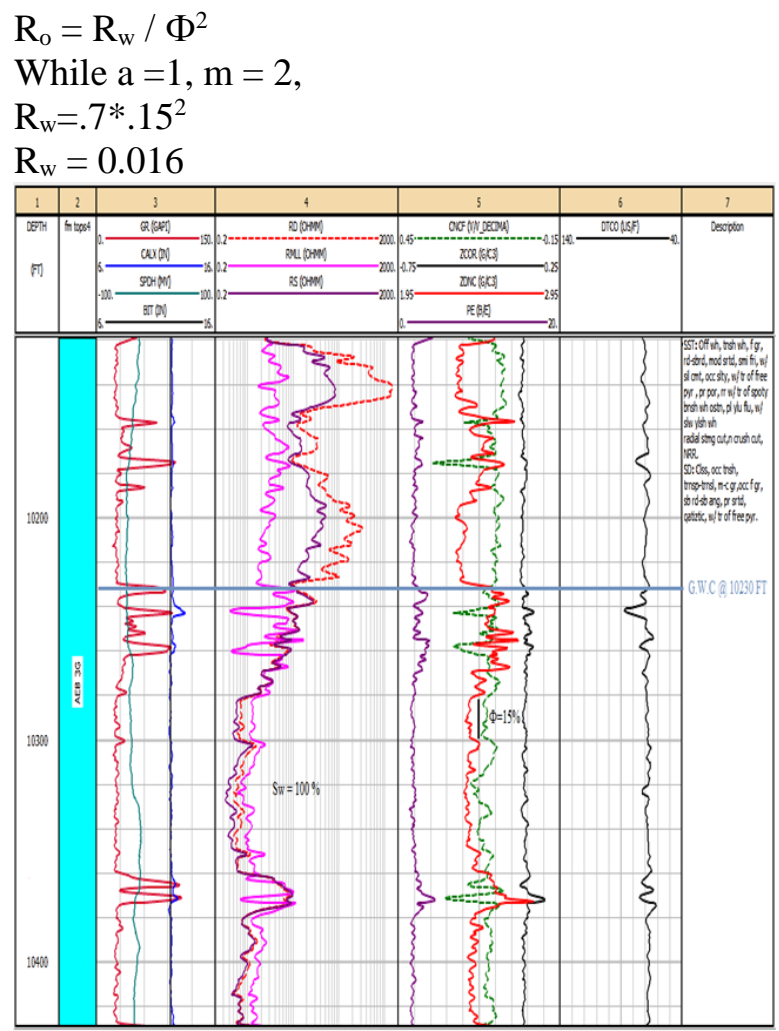

Fig.4: Well Log Data analog format as displayed on the IP program for AEB 3G Member, Jade - 8 well Jade field, North western desert, Egypt 


\section{Graphical Interpretation of Well Log Data}

The cross plot techniques are widely used in the field of well $\log$ data analysis. It represents a preliminary step for locating different mineral constituents. A stream of cross plots between the $\log$ data can be conducted. The technique presented in this article is based essentially on $\Phi \mathrm{N}$

$, \rho_{b}, \mathrm{RT}$ and GR. The following is a full description for the cross plots constructed for (Jade -8) well.

\section{$\left(\rho_{b} . \Phi N_{-} G R z\right.$ plot $)$}

Figure (5) represents a cross-plot between density (ZDNC) versus Neutron (CNCF) and Gamma ray presented as $Z$ axis (right colored bar). The plotted points were chosen to represent good hole conditions. Points located North West direction possess low GR value (20 -30 API) reflect gas effect. Some points plotted just below limestone line trends higher densities and very low neutron may reflect presence of heavy minerals. According to Mud Log Description (fig.6) traces of free pyrite is occasionally present. Points with gradual increase of GR values indicate clay minerals.

It is worth mentioned here that this plot solves for two minerals matrix. Accordingly, it cannot be used for solving complex matrix constituents. To facilitate the interpretation the same plot was constructed for filtered points with low to moderate GR and (caliper $\leq 12.5$ ) (Fig.7) which clearly indicate the pyrite trend which has included in the mineralogical model. Points between sand stone and lime stone possess moderately high GR may represent siltstone rather than carbonate which confirmed through the composite log description.

The $\rho b_{-} \Phi N$ crossplot technique can be extended to give a quick gas porosity correction (Fig.8). For sandstone reservoir we can draw a line parallel to the approximate gas correction line and intersect with the horizontal line at zero limestone porosity. This will be a pivot point to draw intermediate porosity lines $(0-30 \%)$. On this plot porosities for gas points located above sandstone line can be read directly on this porosity lines. These porosities can be correlated with these obtained from gas corrected porosities shown in (Table1) using:

$$
\Phi=\left(\frac{\Phi_{\mathrm{N}}^{2}+\Phi_{\mathrm{D}}^{2}}{2}\right)^{1 / 2}
$$

The most important point here to notice is the very good matching between porosity ranges appear on (Fig.8) with those calculated (Table1). This means that, this graphical technique is valid.

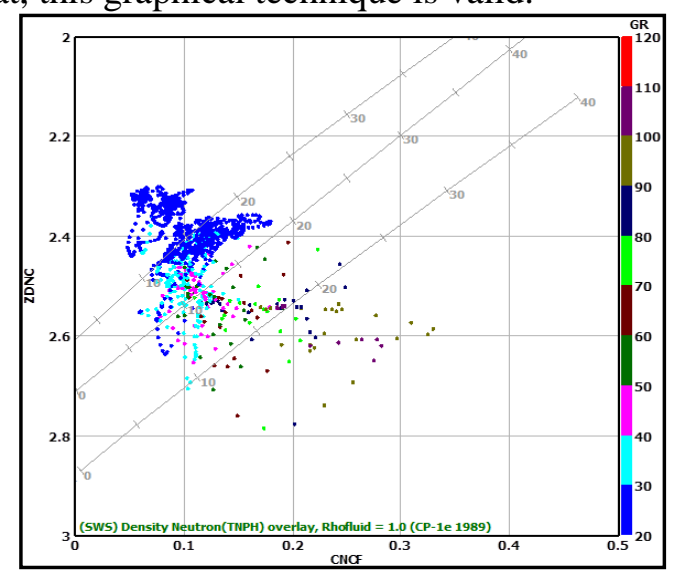

Fig.5: compensated Neutron porosity $(\Phi \mathrm{N})$ versus formation Density $(\rho \mathrm{gm} / \mathrm{cc}$ ) for AEB formation $3 \mathrm{G}$ Member, JADE-08 well, Jade Field, Matruh basin, North Western Desert, Egypt.

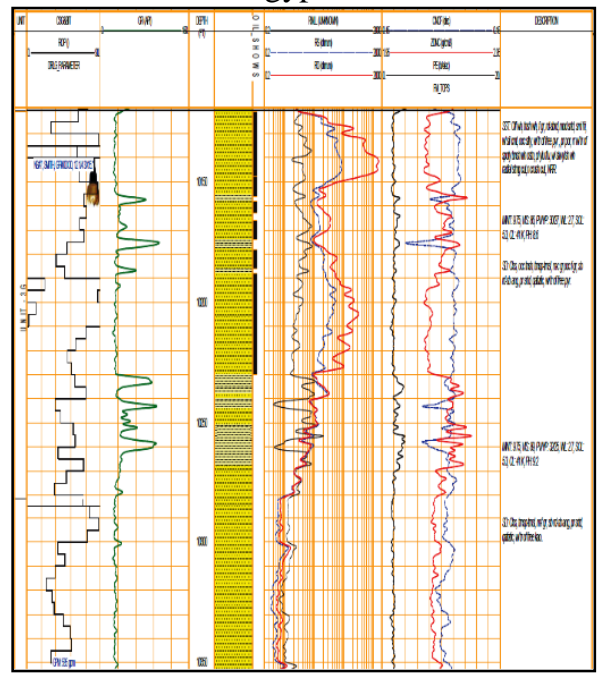

Fig.6: Mud log description for AEB 3G Member, Jade -8 well Jade field, North western desert, Egypt.

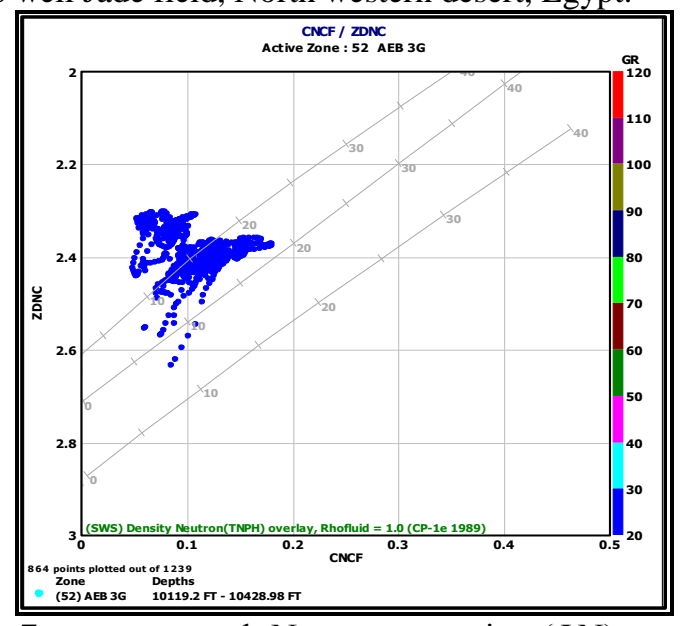

Fig.7: compensated Neutron porosity $(\Phi N)$ versus formation Density ( $\rho \mathrm{b} \mathrm{gm} / \mathrm{cc}$ ) for clean AEB formation 3G Member, JADE-08 well, Jade Field, Matruh basin, North Western Desert, Egypt. 


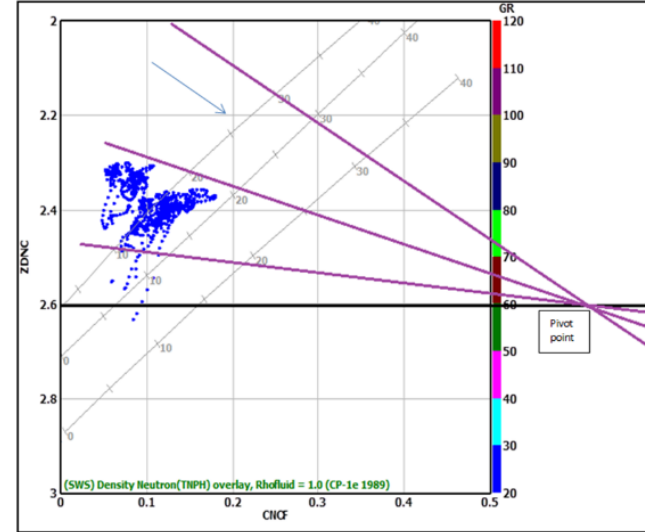

Fig.8: compensated Neutron porosity $(\Phi N)$ versus formation Density ( $\rho b \mathrm{gm} / \mathrm{cc}$ ) for AEB formation $3 \mathrm{G}$ Member, JADE-08 well, Jade Field, Matruh basin, North Western Desert, Egypt.

Table (1): Calculated effective porosity (PHIE) for gas zones using Equation 2

\begin{tabular}{|c|c|}
\hline DEPTH (FT) & PHIE \\
\hline 10124 & 0.17 \\
\hline 10128 & 0.16 \\
\hline 10132 & 0.157 \\
\hline 10136 & 0.161 \\
\hline 10140 & 0.162 \\
\hline 10144 & 0.161 \\
\hline 10148 & 0.124 \\
\hline 10152 & 0.165 \\
\hline 10160 & 0.142 \\
\hline 10172 & 0.113 \\
\hline 10180 & 0.102 \\
\hline 10184 & 0.132 \\
\hline 10188 & 0.121 \\
\hline 10192 & 0.121 \\
\hline 10196 & 0.173 \\
\hline 10200 & 0.172 \\
\hline 10204 & 0.146 \\
\hline 10208 & 0.156 \\
\hline 10212 & 0.158 \\
\hline 10216 & 0.182 \\
\hline 10220 & 0.169 \\
\hline 10224 & 0.166 \\
\hline 10228 & 0.164 \\
\hline
\end{tabular}

$M-N$ plot

This plot depends on three log parameters $\left(\left(\rho_{\mathrm{b}}-\Phi \mathrm{N}_{-}\right.\right.$and $\left.\Delta \mathrm{T}\right)$ with $\mathrm{GR}-\mathrm{Z}$ plot and has its advantages over $\boldsymbol{\rho}_{\mathbf{b}}$ - $\mathbf{\Phi N}$ as it can solve for more than two mineral constituents. (Fig.9) represents $\mathrm{M}-\mathrm{N}$ plot for $3 \mathrm{G}$ member of AEB formation for Jade -8 well which reflect great enhancement for mineralogical model constitution, on this plot calcite is excluded as the majority of points are clustered on quartz. The gas effect is clearly seen as points clustered towards $\mathrm{N}$
- E direction. It is noticed that, few points aligned $\mathrm{S}-\mathrm{W}$ with low gamma ray readings which may be due to presence of pyrite. This plot confirmed the above mentioned matrix constituents.

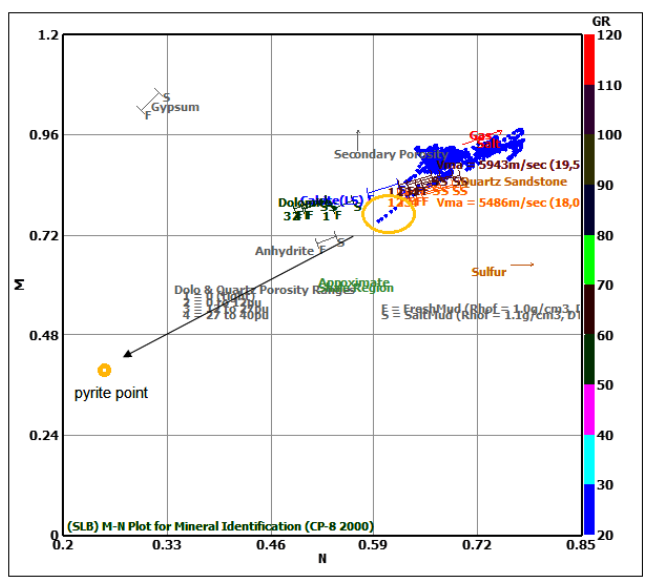

(Fig.9: $\mathrm{M} \mathrm{N}$ plot for AEB formation $3 \mathrm{G}$ unit at JADE08 well Jade Field, - Matruh basin, North Western Desert, Egypt.

\section{Pickett plot:}

Figure (10) represents the Pickett plot for $3 \mathrm{G}$ reservoir at JADE-08 well Jade Field. The Gamma ray was presented as " $Z$ " value in a color code. The red line represents $100 \%$ Sw (Ro line) with " $\mathrm{m}$ " equals 1.88 (slope of the line). The intersection of this line with vertical axis at 1 gives Rw of $0.0186 \Omega \mathrm{m}^{2} / \mathrm{m}$. It is very interesting to notice that this value is the same as those obtained through qualitative interpretation of $0.016 \Omega \mathrm{m}^{2} / \mathrm{m}$.

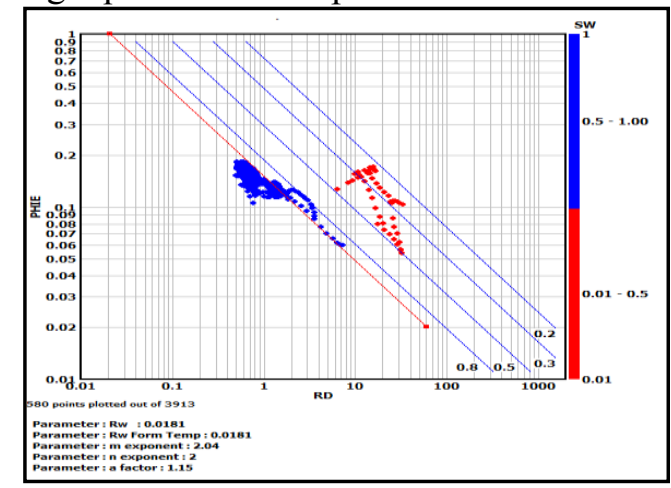

Fig.10: Picket plot for AEB Formation 3G unit at JADE-08 well Jade Field, Matruh basin, North Western Desert, Egypt.

\section{Porosity-Saturation}

Buckle 1965 introduced the most important value for evaluating the reservoir performance. This is done by computing the product of porosity time the water saturation. Reservoir at irreducible water saturation (i.e $\mathbf{\Phi . S w}$ constsnt) will produce clean oil with no water. Buckle that when plotting porosity against water saturation on linear scale 
makes points representing reservoir at irreducible will follow hyperbola with lower values. In this article, logarithmic scales will be used instead. The relation will be as follows (Holmes, etal 2009):

$\log$ Swi $=\log C-\log p h i$

This can be represented graphically on log-log paper (Fig. 11). Points representing irreducible state will be followed straight line with slope of unity. Intersection of this line with Log phi equals one give the constant C. (Fig. 12) represents application to AEB-3G reservoir at JADE-08 well Jade Field. On this plot, red colored points plotted below the violet line, with slope unity, reflect free water production. The constant is 0.03 which confirm the sandstone nature of this reservoir. Pointes plotted above this line that line (blue color) represent movable water production.

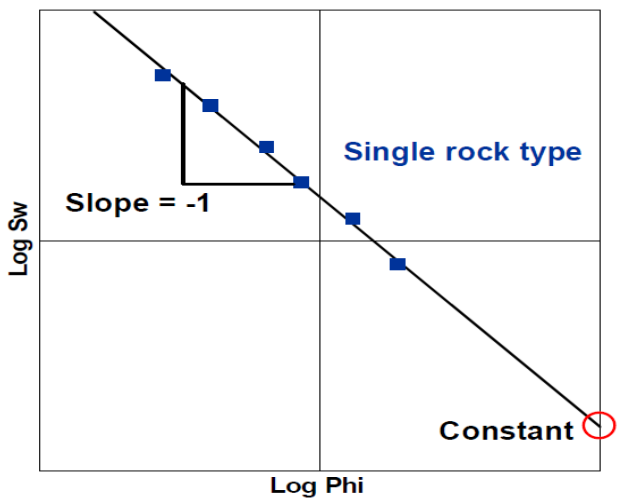

Fig.11: Holmes et.al. (2009) plot for representation of porosity versus water saturation on log-log paper for obtaining the constant " $\mathrm{C}$ ".

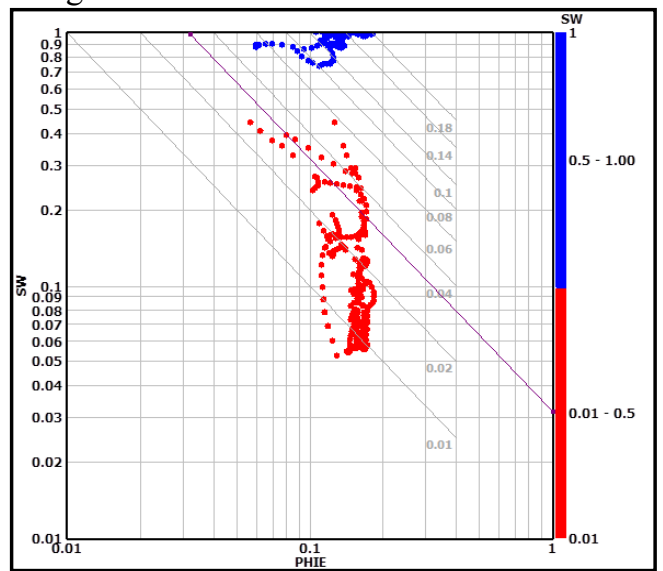

Fig.12: Holmes et.al. (2009) plot for AEB formation 3G unit at JADE-08 well Jade Field, Matruh basin, North Western Desert, Egypt.

\section{THE LITHOSATURATION CROSS PLOT (Fig.13)}

Through this plot, it is very obvious that the upper most part of AEB - 3G member (10120 - 10230
Ft) represent the main productive zone. It reflect a constant and continuous reservoir parameters with $18 \%$ average $\Phi$ and $18 \% \mathrm{Sw}$. the sand stone is the main matrix constituent with some shale streaks. This reservoir can be considered clean. Presences of pyrite traces (violet) are also seen. The majority of the contained gas is movable (red area). The gas zone is separated from the underlying water zone by a relatively high Vsh unit $(10230-10280 \mathrm{Ft})$. This water zone is extended downward to the total depth. It is important here to refer to the very low BVW characterizing excellent to very good reservoir quality and expected to produce free water gas.

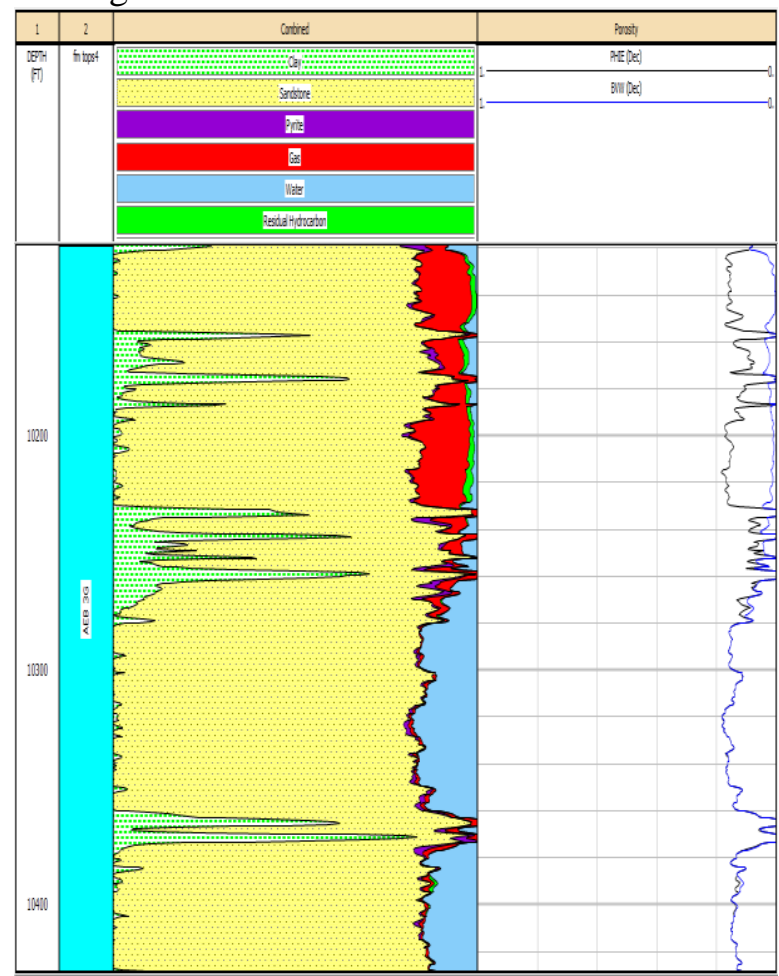

Fig.13: The litho-saturation cross-plot for AEB formation 3G unit at JADE-08 well Jade Field, Matruh basin, North Western Desert, Egypt.

\section{|CONCLUSION}

The presented work shed more light on the importance of the well $\log$ interpretation techniques for evaluating the AEB - $3 \mathrm{G}$ gas reservoir in Matruh Basin, North Western Desert, Egypt. The following are the main conclusions extracted:

1. The gas effect can be eliminated for the sandstone reservoir through graphical presentation for $\rho_{b} \mathrm{Vs} \Phi \mathrm{N}$.

2. The tri porosity cross plot in the form of $\mathrm{M}$ $\mathrm{N}$ greatly enhanced the obtained mineralogical model for $\mathrm{AEB}-3 \mathrm{G}$ member. 
It includes gas effect, presence of pyrite traces and Quartz minerals.

3. The $\Phi$ vs Sw presented on $\log$ - log paper facilitate discrimination and differentiation between gas and water zone for AEB - 3G member in JADE -8 well. The plotted points of AEB - $3 \mathrm{G}$ reservoir were located below straight line with slope unity indicating that reservoir is at irreducible state with free water production.

4. The lithosaturation cross plot give visual and quick method for locating the producing intervals to aid the decision make where to perforate.

5. The AEB $-3 \mathrm{G}$ reservoir characterized by high effective porosity (18\%), low Sw (<20\%) and very low BVW $(<0.02)$.

6. The obtained results were confirmed through mud log description.

\section{References}

Archie, G. E. (1942): The electrical resistivity log as an aid in determining some reservoir characteristics: Petroleum Technology, v. 5 p. $54-$ 62.

Buckles, R.S.(1965): Correlating and averaging connate water saturation data, Journal of Canadian Petroleum Technology, v.9, no.1, p.4252.

EGPC. (1992): In: Western Desert, oil and gas fields, a comprehensive overview.11 $1^{\text {th }}$ Petroleum Exploration and Production Conference, Egyptian General Petroleum Corporation, Cairo. pp. 1-431.
Guiraud, R., Bosworth,W.,(1999): Phanerozoic geodynamic evolution of north- eastern Africa and the north western Arabian platform. Rev.Tectonophysics 315, 73108.

Holmes, M., Holmes, A., Holmes, D.,(2009): Relationship between Porosity and Water Saturation: Methodology to Distinguish Mobile from Capillary Bound Water AAPG Annual Convention, Denver, Colorado, June 7-10, 2009.

Moustafa, A.R. (2008): Mesozoice Cenozoic basin evolution in the northern Desert of Egypt. In: Salem, M., El-Arnauti, A., Saleh, A. (Eds.), 3rd Symposium Sedimentary Basins of Libya, The Geology of East Libya, vol. 3, pp. 29-46.

Moustafa, A.R., EL-Barkooky, A.N., Mahmoud, A., Badran, A.M., Helal, M.A., Nour EL din, M. and Fathy, H. (2002): Matruh basin: hydrocarbon plays in an inverted Jurassic- Cretaceous rift basin in the northern Western Desert of Egypt. Am. Assoc. Petrol. Geol. Int. Meeting (Cairo, Oct. 2002), Abstract.

Schlumberger (1995) In: Geology of Egypt. Paper presented at the Well Evaluation Conference, Schlumberger, Cairo, pp 58-66.

Shalaby MR, Hakimi MH, Abdullah WH (2011) Geochemical characteristics and hydrocarbon generation modeling of the Jurassic source rocks in the Shoushan Basin, north Western Desert, Egypt. Mar Petrol Geol 28(9):1611-1624.

Sultan, N. and Halim, M.A. (1988). Tectonic framework of northern Western Desert, Egypt \& its effect on hydrocarbon accumulations. Proc. 9'" E. G.P. C. Petrol. Explor. \& Prod. Conf., 2, 1-22.

\section{الملخص العربي \\ عنوان البحث: تحليل بيانات سجل الآبار لتقييم مكامن الغاز والرمل لتكوين علم البويب، عضو بَG، بئر \\ Jade-8

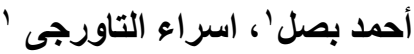 \\ ' ق قسم الجيولوجيا - كلية العلوم - جامعة دمياط}

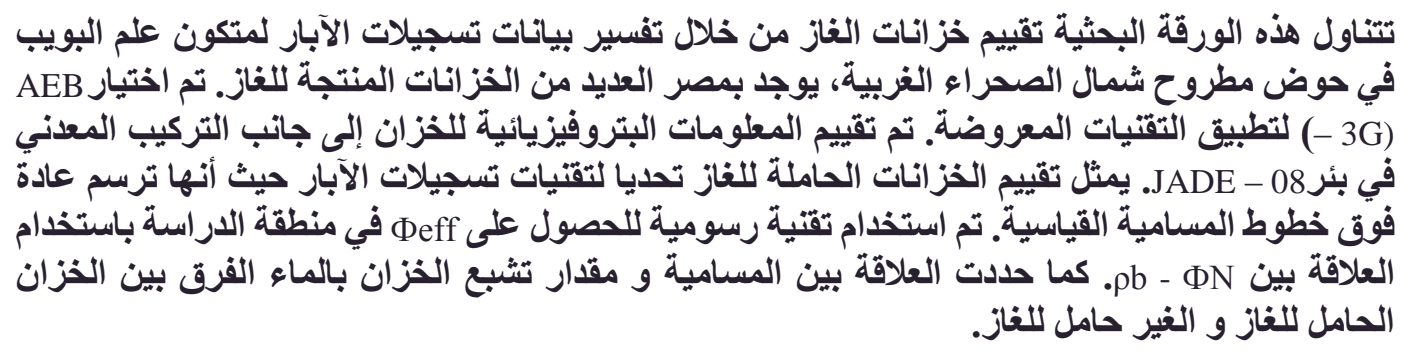

